\title{
Descending control of nociception in insects?
}

\author{
Matilda Gibbons ${ }^{*}$, Sajedeh Sarlak ${ }^{2} \&$ Lars Chittka $^{{ }^{*}}$
}

${ }^{1}$ School of Biological and Behavioural Sciences, Queen Mary University of London, London, UK; E1 4NS

${ }^{2}$ Faculty of Agricultural Science and Engineering, University of Tehran, 1417935840; Iran

*Corresponidng: Lars Chittka, School of Biological and Behavioural Sciences, Queen Mary, University of London, Mile End Road,, London, E1 4NS, UK, *44 (0) 207 8823043 Email: l.chittka@gmul.ac.uk

\begin{abstract}
Modulation of nociception allows animals to prioritise their survival by adapting their behaviour in different contexts. In mammals, this is executed by neurons from the brain, and is referred to as the descending control of nociception. Whether insects have this control, or have the neural circuits underpinning it, has not been clarified. Here, we review evidence supporting descending control of nociception control in insects, and consider which neuronal sub-types and brain areas may be involved.
\end{abstract}

Keywords: nociception; pain; modulation of nociception; insects; descending control of nociception

\section{Descending control of nociception}

Nociception is the detection of potentially or actually damaging stimuli, which is mediated by specialised receptors: nociceptors (Tracey, 2017). Nociception can be accompanied by the feeling of pain, which is a negative subjective experience generated by the brain (Auvray et al., 2010; Birch et al., 2020). Nociception and/or pain can be inhibited or facilitated (modulated) by descending neurons from the brain called "the descending pain controls" (Millan, 2002; Ossipov et al., 2010). There are distinctive mechanisms behind modulation of nociception and modulation of pain, and recent studies have uncovered that certain contexts or stimuli can modulate pain report while keeping nociceptive reflexes unchanged (Morélot-Panzini et al., 2014; Rhudy et al., 2006, 2006; Yashiro et al., 2011), and vice versa, where nociceptive reflexes are modulated but pain report is unchanged (Rhudy et al., 2018)). Therefore, in animals where the distinction of pain and nociception has not yet been explored experimentally, it has been suggested we refer to descending control of pain as "descending control of nociception" (Bannister et al., 2021). We will adopt this terminology in this review.

Descending control of nociception has an important adaptive function, allowing the adjustment of behaviour to different contexts to prioritise survival (Millan, 2002). For example, if an animal is injured during a fight, the dampening of their nociceptive processing may increase the animal's fighting performance by ensuring they do not waste time or energy on responding to the injury. Likewise, when the animal has returned to safety, the descending controls can facilitate nociceptive processing, encouraging the animal to protect the injured location so that its healing is promoted. These arguments would make adaptive sense in any animal. Surprisingly, however, in the most speciose animal class, the 
insects, such descending pain controls have been little investigated (Forbes et al., 2018; Im \& Galko, 2012).

Nociception, and nociceptive behaviour, is well documented in insects (e.g. Hwang et al., 2007; Tracey et al., 2003). Further, insect nociceptive processing can be modulated (e.g. (Khuong et al., 2019; Tabuena et al., 2017). For example, the larval tobacco hawkmoth (Manduca sexta) shows a defensive nociceptive behaviour in response to a noxious pinch, performing a rapid bending response towards the pinch site (Figure 1), and this response can be sensitised by tissue damage (Tabuena et al., 2017; Walters et al., 2001). However, the specific mechanisms and pathways of modulation of nociception in insects have only been partially uncovered, and is it not fully established whether the modulation involves the brain. In this review, we suggest that insects have descending modulation of nociception, based on behavioural and anatomical evidence. 


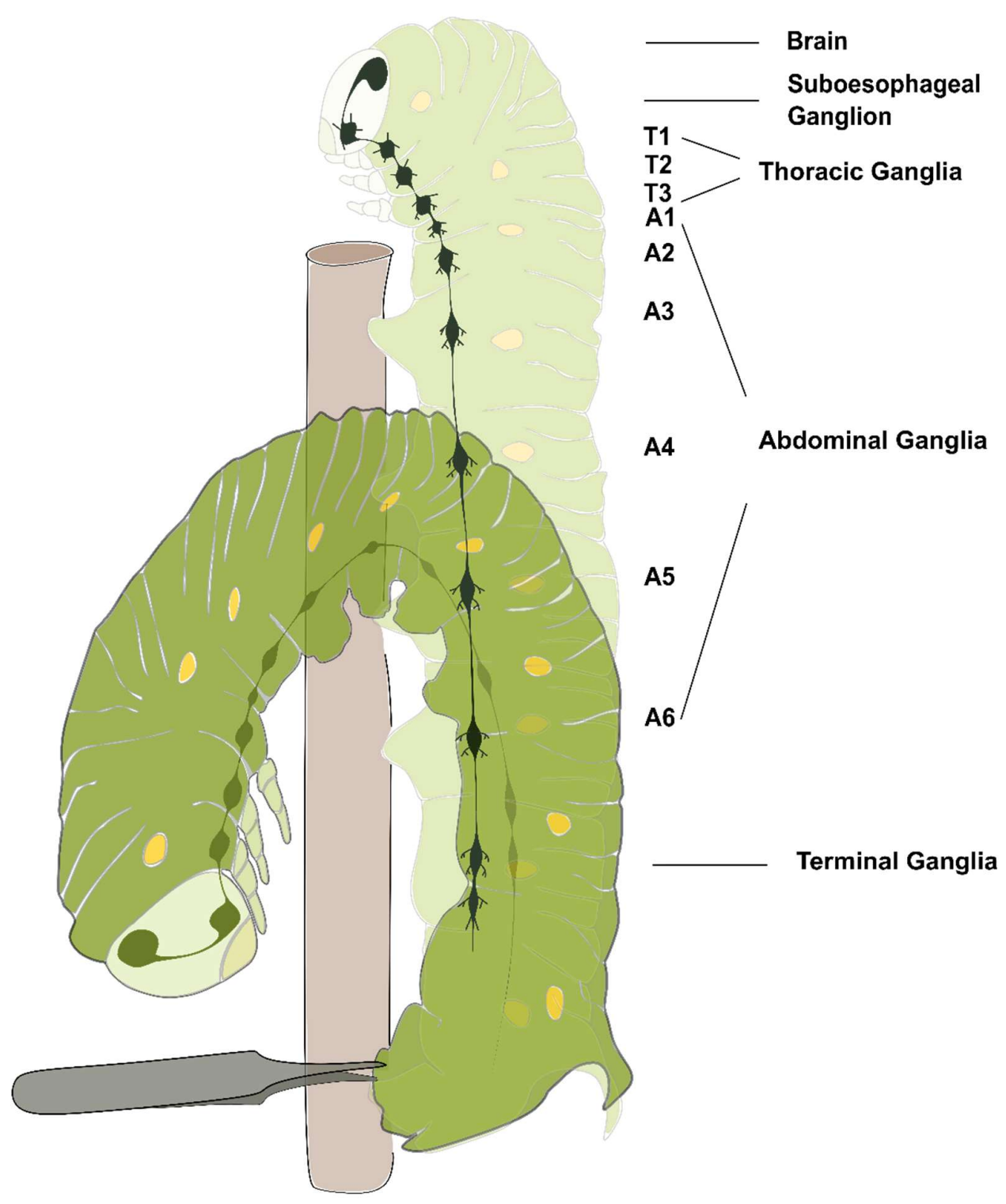

Figure 1. The defensive strike response and the nervous system of larval tobacco hawkmoth Manduca sexta. The tobacco hawkmoth caterpillar shows a rapid bending response towards the site of the pinching stimulation on the terminal segment of the abdomen (source of the stimulation). The success of attackers such as birds that bite caterpillars can be reduced by the high velocity and precise targeting of the strike. This defensive strike response is faster and larger after repeated noxious stimulation and results in nociceptive sensitization (Walters et al., 2001). Adapted from Walters et al., 2001.

\section{Sensitisation of nociceptive responses in insects}

All insects exhibit nocifensive behaviour, a class of behaviours that occur in response to noxious stimuli and have the purpose of reducing exposure to the stimulus. An example of a nocifensive behaviour in fruit flies is the moving away from a floor heated to $46^{\circ} \mathrm{C}$ (e.g. (Neely et al., 2010)). Nociceptive sensitisation occurs when the intensity of normal nocifensive behaviour is increased, or the threshold for the induction of the nocifensive behaviour is lowered (Im \& Galko, 2012). In mammals, this sensitisation can occur through molecular mechanisms at the site of 
damage (Babcock et al., 2011), or from activation of faciliatory projection neurons in the rostral ventral medulla (Tillu et al., 2008). Both of these mechanisms ultimately increase the nociceptive neurons' responsiveness to noxious stimuli.

Insects are capable of nociceptive sensitisation. For example, in larval Manduca sexta, the defensive strike response to a noxious stimulus is faster and greater after repeated noxious stimulation (Walters et al., 2001) (Figure 1). Similarly, in fruit flies, injury of epidermal cells by ultraviolet light increases the speed of the flies' withdrawal response from both sub-noxious and noxiously-heated thermal stimuli (Babcock et al., 2009).

Some of the molecular mechanisms underlying sensitisation of nociception in insects have been revealed. Peripheral mechanisms involve some of the same molecules responsible for human nociceptive sensitisation. For example, in fruit flies, like humans, signalling molecules including Hedgehog, tachykinin and tumour necrosis factor are involved in the sensitisation of the nociceptors (Babcock et al., 2009, 2011; Im et al., 2015). Also similar to humans, central mechanisms have been suggested; for example, in larval Manduca sexta, sensitisation of the defensive strike response is associated with a reduction in firing threshold of the central connective nerve, and can be blocked using N-methyl-D-aspartate receptor and hyperpolarization-activated, cyclic nucleotide-gated antagonists (Tabuena et al., 2017). Further, in fruit flies, a loss of GABA inhibition in the ventral nerve cord causes nociceptive sensitisation (Khuong et al., 2019). However, whether the brain is involved in this sensitisation is unknown.

\section{Inhibition of nociceptive responses in insects}

Inhibition, as opposed to sensitisation, of nociceptive responses in insects has gained less attention. However, there is behavioural evidence of reductions in normal nocifensive behaviour in insects in certain situations. For instance, female mantids will consume the male during copulation, and the male appears to supress his normal nocifensive behaviour to allow this (Schwartz et al., 2016). This is most likely because the male has fitness benefits from being consumed, as sacrificing his body as nutrition for the female increases the number, size and survivorship of the offspring (Schwartz et al., 2016). Another example of inhibition of nocifensive behaviour in insects is how fruit flies and bumblebees (Bombus terrestris) will overcome their avoidance of noxious stimuli to obtain an appetitive stimulus (Gibbons et al., 2022; Kaun et al., 2011). Further, insects have been noted to act visibly 'normal' after injury, by continuing to feed or not altering their behaviour (Eisemann et al., 1984). This evidence has been suggested to indicate the absence of pain in insects (Mikhalevich \& Powell, 2020; Smith, 1991); however, more likely, it demonstrates how certain contexts can reduce the nocifensive behaviour of an insect (Gibbons \& Sarlak, 2020).

The mechanisms behind inhibition of nociceptive responses are poorly understood in most insects. In fruit flies, there are second-order interneurons in the ventral nerve cord that are activated by nociceptors and integrate different sensory stimuli (Lopez-Bellido et al., 2019), as well as triggering nocifensive rolling behaviour in fruit fly larvae ( $\mathrm{Hu}$ et al., 2020; Kaneko et al., 2017; Ohyama et al., 2015). Two types of these interneurons, Basin-4 and A08n, are involved in the inhibition of nociceptive signalling in fruit fly larvae, via an inhibitory feedback loop 
with serotoninergic neurons (Figure 2b) (Kaneko et al., 2017). Basin-4 and A08n also activate leucokinin neurons in the abdominal ganglion of the fruit fly larva, which are required for escape behaviour from noxious stimuli (Hu et al., 2020), and these neurons express the serotonin receptor 5-HT1B (Okusawa et al., 2014). This suggests that serotonin may also be able to inhibit nociceptive processing via leucokinin neuron signalling. Another mechanism of inhibition of nociception that has been uncovered is GABAergic neurons, which inhibit the activity of these abdominal ganglion leucokinin neurons (Hu et al., 2020). These findings demonstrate that inhibition of nociception in insects is possible via molecular pathways (see Figure 2b). However, again, whether this inhibition can occur via descending controls from the brain remains unclear.

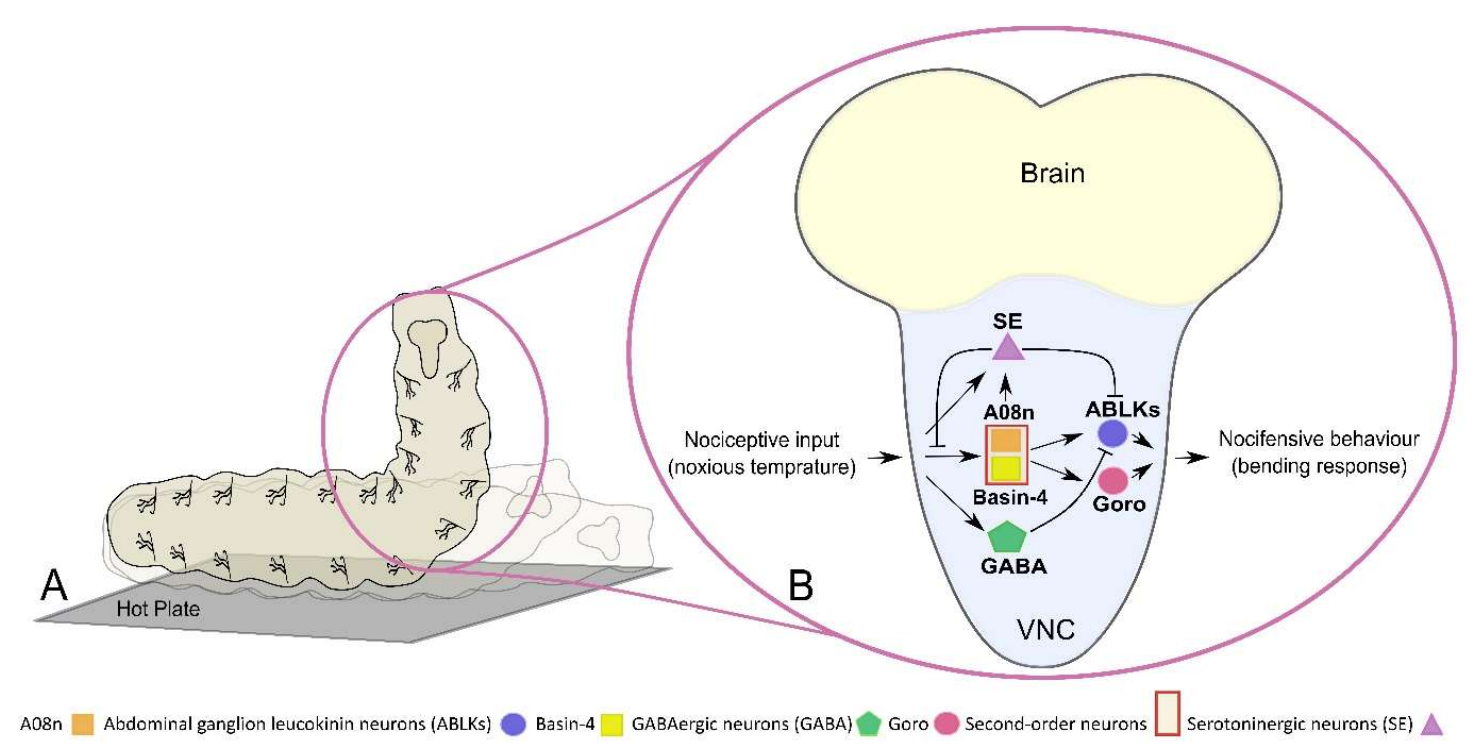

Figure 2. Nocifensive response to noxious stimulus and possible molecular pathways for inhibition of nociception in larval Drosophila melanogaster. A) Nocifensive rolling:, A corkscrew -like rolling response to noxious temperature that acts as a protective escape behaviour (Hwang et al., 2007). B) Putative molecular pathway for inhibition of nocifensive behaviour in VNC (ventral nerve cord). Nociceptive input activates second-order neurons (SONs) such as A08n and Basin-4, serotonergic neurons and GABAergic neurons. SONs then activate abdominal ganglion leucokinin neurons and Goro neurons, which induce nocifensive behaviour. GABAergic and serotonergic neurons inhibit the activity of abdominal ganglion leucokinin neurons. Serotonergic neurons inhibit synaptic transmission between nociceptive input from nociceptors and SONs.

\section{Descending nociception controls in insects?}

Modulation of nociception in insects has been demonstrated behaviourally, and some of the molecular mechanisms underlying this have been identified (see above). In this section, we explore whether the modulation of nociception in insects can be activated by the brain, via descending controls. To explore this possibility, it is useful to contemplate how this pathway works in organisms better studied in this regard. In mammals, nociceptors transmit the information to the dorsal horn of the spinal cord, and the signal is then sent to the brain via ascending projection neurons (Bannister, 2019) (see Figure 3). The periaqueductal gray in the midbrain receives nociceptive inputs, as well as inputs from 
cortical brain areas involved in pain processing, and transmits the signal to the rostral ventromedial medulla (RVM) (Ossipov et al., 2014). The RVM projects to the dorsal horn and has distinct cell types which descend to the spinal cord and can inhibit or facilitate nociception (Ossipov et al., 2014).

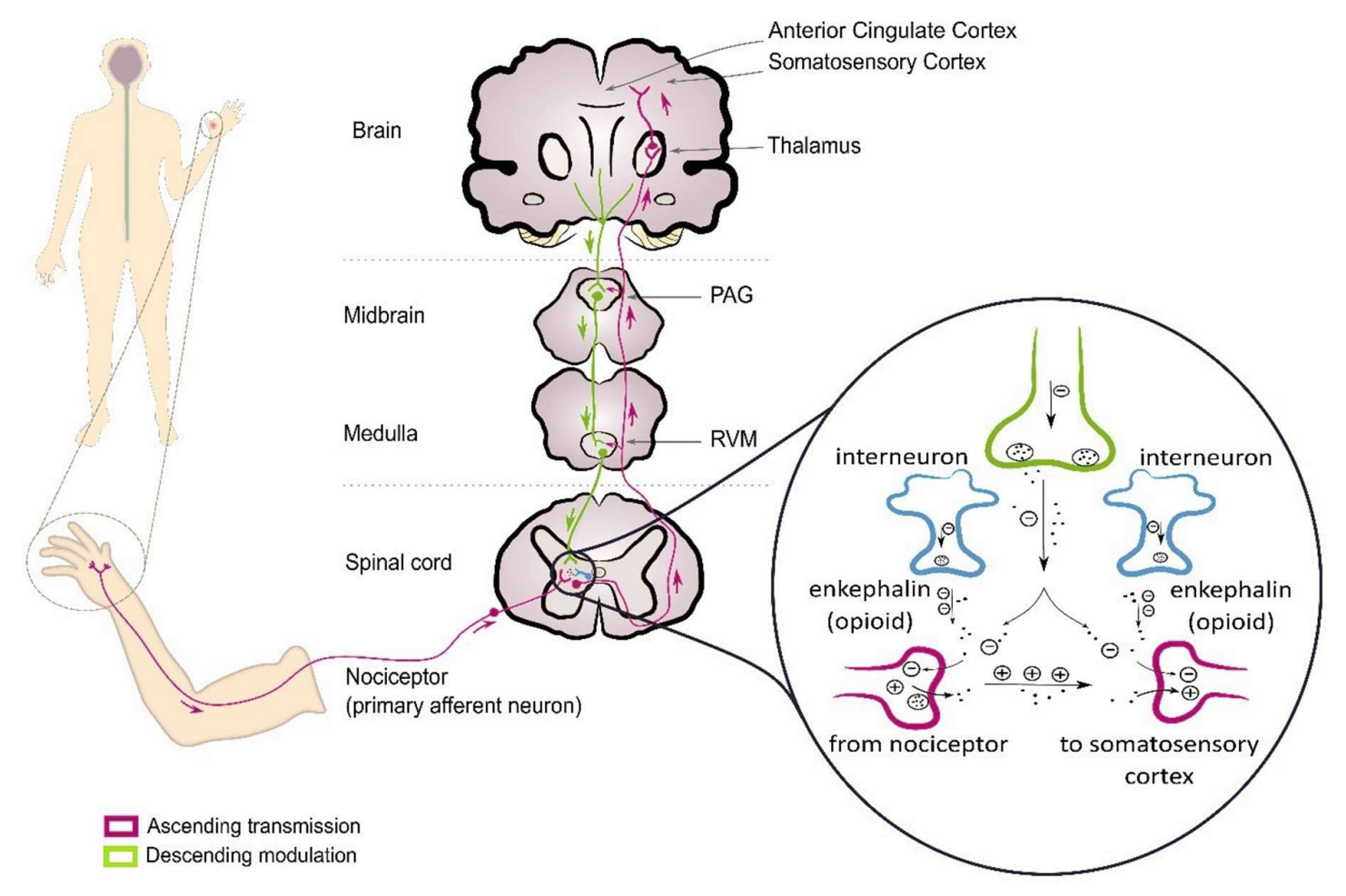

Figure 3. Human descending and ascending pain pathways. Primary afferent neurons project to secondary neurons in the dorsal horn of the spinal cord. Axons of the second-order neurons project to the thalamus, the rostral ventral medulla (RVM) and the periaqueductal grey (PAG). With their cell bodies in the thalamus, third-order neurons project to the somatosensory cortex to encode the sensorydiscriminate aspects of pain. They also project to other areas, such as the anterior cingulate cortex, which are involved in the affective aspect of pain. These areas provide input to the PAG, which communicates with the RVM to send modulatory projections to the spinal cord. Such neurons influence enkephalin interneurons which can inhibit the transmission of nociception through primary afferent neurons. Adapted from Ossipov et al., 2010.

Behavioural evidence suggesting the brain is involved in modulation of nociception exists in the American cockroach (Periplaneta americana), where the threshold required for nocifensive escape behaviour is increased after being stung in the suboesophageal ganglion in the brain by the parasitic jewel wasp (Ampulex compressa) (Gal \& Libersat, 2010; Gavra \& Libersat, 2011; Haspel et al., 2002). This indicates that the insect brain can modulate nocifensive behaviour. Further, stimuli that are processed by the insect brain can inhibit nocifensive behaviour. For example, the taste of sugar processed in the fruit fly brain (Wang et al., 2004), and attraction to sugar (or an odour that was previously associated with sugar), supresses avoidance of noxious stimuli in both fruit flies and bumblebees (Gibbons et al., 2022; Kaun et al., 2011). Similarly, the processing of food-deprivation in the brain reduces the nocifensive jump response to noxious heat in fruit flies (Ohashi \& Sakai, 
2018); this apparently relies on the brain, as the same reduction is not observed in decapitated flies (although basic nociception is maintained) (Ohashi \& Sakai, 2018). Taken together, behavioural evidence suggests that, like mammals, the insect brain can exert descending control over nociceptive processing.

Anatomical evidence also supports the existence of insect descending nociception controls. Studies have identified neurons that descend from the brain to the nerve cord and are involved in insect nociception. For example, in Drosophila larvae, axons descend from the brain to the Basin and Goro neurons, which mediate the nocifensive rolling response (a corkscrew-like roll in response to noxious stimuli (Hwang et al., 2007) (Ohyama et al., 2015) (Figure 2). In adult Drosophila, some neurons that connect the brain and ventral nerve cord express the protein 'Straightjacket', a calcium channel that mediates nociceptive hypersensitivity (Khuong et al., 2019; Neely et al., 2010).

\section{Characteristics of the putative insect descending nociception controls}

Given the evidence discussed above, it is plausible that insects have descending nociception controls to modulate their nocifensive behaviour in certain contexts. Here, we discuss the putative chemical and anatomical characteristics of these controls. Mammalian descending pain controls rely strongly on opioid signalling (Ossipov et al., 2014), so it has been suggested that insects descending controls might also involve opioid signalling (Emanuel \& Libersat, 2019). However, genomic studies have determined that insects do not have genes that code for opioid receptors or peptides (Elphick et al., 2018; Jékely, 2013; Kreienkamp et al., 2002; Mirabeau \& Joly, 2013). Thus, it is more likely that another neuropeptide or neurotransmitter functions as the signalling molecule for the putative insect descending nociception controls.

Leucokinin, a neuropeptide with many functions in insects, including the modulation of nocifensive behaviour (see Figure 4) (Hu et al., 2020; Nässel, 2021), is a potential candidate signalling molecule for the insect descending nociception controls. There are leucokinin neurons that descend from the suboesophageal ganglia to the ventral nerve cord (de Haro et al., 2010; Hu et al., 2020). Importantly, these neurons are able to supress nocifensive behaviour (Ohashi and Sakai, 2018). Specifically, they are required for the reduction of nocifensive behaviour in hungry fruit flies (Ohashi \& Sakai, 2018). This is interesting because, as mentioned earlier, the jewel wasp modulates the American cockroach's nocifensive behaviour by stinging in the suboesophageal ganglia (Gal \& Libersat, 2010; Gavra \& Libersat, 2011; Haspel et al., 2002). Since taste is also represented in the suboesophageal ganglia in insects (Kvello et al., 2006; Marella et al., 2006; Wang et al., 2004), integration of competing stimuli may occur here. Leucokinin neurons may be, therefore, the output neurons of the suboesophageal ganglion that can modulate behaviour according to certain contexts or stimuli. 


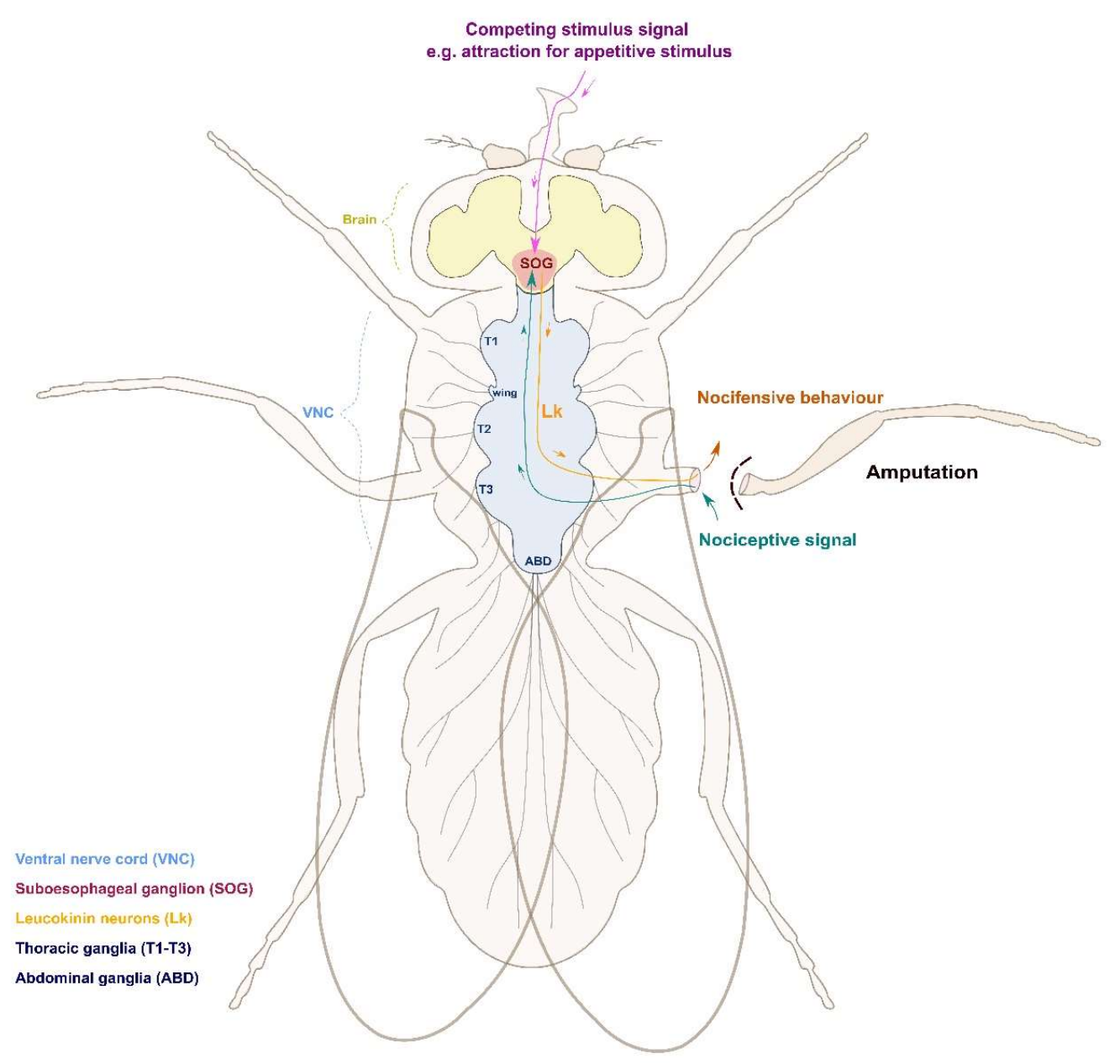

Figure 4. Putative insect descending nociception controls in Drosophila melanogaster adult. Amputation of the middle leg causes nocifensive behaviour in fruit flies; and this nocifensive behaviour can be reduced when the fly is hungry. This is mediated by Leucokinin neurons (Lk). The nociceptive signal is transmitted to the ventral nerve cord (VNC), which can cause nocifensive behaviour, but is also transmitted along ascending fibres to the suboesophageal ganglion (SOG). A competing stimulus signal, such as attraction to an appetitive odour or food, is also transmitted to the suboesophageal ganglion. The appetitive and aversive signals are integrated here. Leucokinin neurons descending from the suboesophageal ganglion can suppress the nocifensive behaviour depending on the integrated information.

\section{The significance of insect descending nociception controls}

The presence of descending nociception controls in insects is important and interesting for many areas of insect and human neuroscience. Descending control of nociception in humans can also affect pain perception, so it could be argued that pain is also affected in non-verbal animals. This is certainly the accepted argument for mammals such as mice, where a reduction in nociceptive behaviour is accepted as equalling a reduction in pain (e.g. (Ikeda et al., 2014)). In insects, however, this argument is not widely accepted. This, perhaps, is because insect behaviour has been viewed as governed largely by instinct, with their behaviour towards injuries likened to robots (Adamo, 2016). In line with this, various authors have denied the existence of pain in insects (Adamo, 2016; Eisemann et al., 1984; Smith, 1991). 
The presence of descending controls makes it at least plausible that insects have painful experiences. Recent evidence demonstrating sentience-linked cognitive abilities in some insects (Bateson et al., 2011; Dinges et al., 2017; Galili et al., 2011; Solvi et al., 2016, 2020; Yarali et al., 2008) supports this idea, as well as studies indicating pain perception in other invertebrates (e.g. (Appel \& Elwood, 2009; Crook, 2021). This is important morally, as insects are subjected to potentially-painful stimuli in research and farming (Bear, 2021). It is also an important consideration for modelling human pain disorders. The fruit fly (Drosophila melanogaster) is currently used as a model organism for human pain research, because of similarities in the genetics and behavioural responses to human nociception (Milinkeviciute et al., 2012). The abnormal and persistent pain states in humans seem to occur due to dysfunction of descending pain controls (Ossipov et al., 2014), so, if insects have descending nociception controls, they could potentially be viable models for human pain disorders.

\section{Conclusion}

We have argued that insects most likely have descending nociception controls, based on behavioural, molecular and anatomical neuroscience evidence. Behaviourally, changes to the insect brain can change their nocifensive behaviour, whether this change is physical manipulation (e.g. (Gal \& Libersat, 2010) or the processing of motivational stimuli (Kaun et al., 2011; Ohashi \& Sakai, 2018). At a molecular level, insects have molecular pathways that can inhibit nocifensive behaviour, peripherally and centrally. Anatomically, insects have descending neuronal projections from the brain to the ventral nerve cord, where nocifensive behaviour is executed. Future research should aim to further characterise modulation of nocifensive behaviour, and whether this is associated with pain in insects, as well to elucidate the neuronal and molecular pathways of descending control of nociception in insects.

Acknowledgments: We thank Bing Ye for comments on the manuscript and Peter Skorupski for discussions about the content.

\section{References:}

Adamo, S. A. (2016). Do insects feel pain? A question at the intersection of animal behaviour, philosophy and robotics. Animal Behaviour, 118, 75-79. https://doi.org/10.1016/j.anbehav.2016.05.005

Appel, M., \& Elwood, R. W. (2009). Motivational trade-offs and potential pain experience in hermit crabs. Applied Animal Behaviour Science, 119(1), 120-124. https://doi.org/10.1016/j.applanim.2009.03.013

Auvray, M., Myin, E., \& Spence, C. (2010). The sensory-discriminative and affective-motivational aspects of pain. Neuroscience $\mathcal{E}$ Biobehavioral Reviews, 34(2), $214-223$. https://doi.org/10.1016/j.neubiorev.2008.07.008

Babcock, D. T., Landry, C., \& Galko, M. J. (2009). Cytokine signaling mediates UV-induced nociceptive sensitization in Drosophila larvae. Current Biology, 19(10), 799-806. https://doi.org/10.1016/j.cub.2009.03.062

Babcock, D. T., Shi, S., Jo, J., Shaw, M., Gutstein, H. B., \& Galko, M. J. (2011). Hedgehog signaling regulates nociceptive sensitization. Current Biology, 21(18), 1525-1533. https://doi.org/10.1016/j.cub.2011.08.020

Bannister, K. (2019). Descending pain modulation: Influence and impact. Current Opinion in Physiology, 11, 62-66. https://doi.org/10.1016/j.cophys.2019.06.004 
Bannister, K., Kucharczyk, M. W., Graven-Nielsen, T., \& Porreca, F. (2021). Introducing descending control of nociception: A measure of diffuse noxious inhibitory controls in conscious animals. PAIN, 162(7), 1957-1959. https://doi.org/10.1097/j.pain.0000000000002203

Bateson, M., Desire, S., Gartside, S. E., \& Wright, G. A. (2011). Agitated honeybees exhibit pessimistic cognitive biases. Current Biology, 21(12), 1070-1073. https://doi.org/10.1016/j.cub.2011.05.017

Bear, C. (2021). Making insects tick: Responsibility, attentiveness and care in edible insect farming. Environment and Planning E: Nature and Space, 4(3), 1010-1030. https://doi.org/10.1177/2514848620945321

Birch, J., Schnell, A. K., \& Clayton, N. S. (2020). Dimensions of animal consciousness. Trends in Cognitive Sciences, 24(10), 789-801. https://doi.org/10.1016/j.tics.2020.07.007

Crook, R. J. (2021). Behavioral and neurophysiological evidence suggests affective pain experience in octopus. IScience, 24(3), 102229. https://doi.org/10.1016/j.isci.2021.102229

de Haro, M., Al-Ramahi, I., Benito-Sipos, J., López-Arias, B., Dorado, B., Veenstra, J. A., \& Herrero, P. (2010). Detailed analysis of leucokinin-expressing neurons and their candidate functions in the Drosophila nervous system. Cell and Tissue Research, 339(2), 321-336. https://doi.org/10.1007/s00441-009-0890-y

Dinges, C. W., Varnon, C. A., Cota, L. D., Slykerman, S., \& Abramson, C. I. (2017). Studies of learned helplessness in honey bees (Apis mellifera ligustica). Journal of Experimental Psychology: Animal Learning and Cognition, 43(2), 147-158. https://doi.org/10.1037/xan0000133

Eisemann, C., Jorgensen, W., Merritt, D., Rice, M., Cribb, B., Webb, P., \& Zalucki, M. (1984). Do insects feel pain? - A biological view. Experientia, 40, 164-167. https://doi.org/10.1007/BF01963580

Elphick, M. R., Mirabeau, O., \& Larhammar, D. (2018). Evolution of neuropeptide signalling systems. Journal of Experimental Biology, 221(3). https://doi.org/10.1242/jeb.151092

Emanuel, S., \& Libersat, F. (2019). Nociceptive pathway in the cockroach Periplaneta americana. Frontiers in Physiology, 0. https://doi.org/10.3389/fphys.2019.01100

Forbes, A. A., Bagley, R. K., Beer, M. A., Hippee, A. C., \& Widmayer, H. A. (2018). Quantifying the unquantifiable: Why Hymenoptera, not Coleoptera, is the most speciose animal order. BMC Ecology, 18(1), 21. https://doi.org/10.1186/s12898-018-0176-x

Gal, R., \& Libersat, F. (2010). A wasp manipulates neuronal activity in the sub-esophageal ganglion to decrease the drive for walking in its cockroach prey. PLOS ONE, 5(4), e10019. https://doi.org/10.1371/journal.pone.0010019

Galili, D. S., Lüdke, A., Galizia, C. G., Szyszka, P., \& Tanimoto, H. (2011). Olfactory trace conditioning in Drosophila. Journal of Neuroscience, 31(20), 7240-7248. https://doi.org/10.1523/JNEUROSCI.666710.2011

Gavra, T., \& Libersat, F. (2011). Involvement of the opioid system in the hypokinetic state induced in cockroaches by a parasitoid wasp. Journal of Comparative Physiology. A, Neuroethology, Sensory, Neural, and Behavioral Physiology, 197(3), 279-291. https://doi.org/10.1007/s00359-010-0610-9

Gibbons, M., \& Sarlak, S. (2020). Inhibition of pain or response to injury in invertebrates and vertebrates. Animal Sentience, 5(29). https://doi.org/10.51291/2377-7478.1649

Gibbons, M., Versace, E., Crump, A., Baran, B., \& Chittka, L. (2022). Motivational trade-offs in bumblebees (p. 2022.02.04.479111). bioRxiv. https://doi.org/10.1101/2022.02.04.479111

Haspel, G., Rosenberg, L. A., \& Libersat, F. (2002). Direct Injection of Venom by a Predatory Wasp into Cockroach Brain.

Hu, Y., Wang, C., Yang, L., Pan, G., Liu, H., Yu, G., \& Ye, B. (2020). A neural basis for categorizing sensory stimuli to enhance decision accuracy. Current Biology, 30(24), 4896-4909.e6. https://doi.org/10.1016/j.cub.2020.09.045

Hwang, R. Y., Zhong, L., Xu, Y., Johnson, T., Zhang, F., Deisseroth, K., \& Tracey, W. D. (2007). Nociceptive neurons protect Drosophila larvae from parasitoid wasps. Current Biology, 17(24), 2105-2116. https://doi.org/10.1016/j.cub.2007.11.029

Ikeda, H., Takasu, S., \& Murase, K. (2014). Contribution of anterior cingulate cortex and descending pain inhibitory system to analgesic effect of lemon odor in mice. Molecular Pain, 10(1), 14. https://doi.org/10.1186/1744-8069-10-14 
Im, S. H., \& Galko, M. J. (2012). Pokes, sunburn, and hot sauce: Drosophila as an emerging model for the biology of nociception. Developmental Dynamics, 241(1), 16-26. https://doi.org/10.1002/dvdy.22737

Im, S. H., Takle, K., Jo, J., Babcock, D. T., Ma, Z., Xiang, Y., \& Galko, M. J. (2015). Tachykinin acts upstream of autocrine Hedgehog signaling during nociceptive sensitization in Drosophila. ELife, 4, e10735. https://doi.org/10.7554/eLife.10735

Jékely, G. (2013). Global view of the evolution and diversity of metazoan neuropeptide signaling. Proceedings of the National Academy of Sciences, 110(21), 8702-8707. https://doi.org/10.1073/pnas.1221833110

Kaneko, T., Macara, A. M., Li, R., Hu, Y., Iwasaki, K., Dunnings, Z., Firestone, E., Horvatic, S., Guntur, A., Shafer, O. T., Yang, C.-H., Zhou, J., \& Ye, B. (2017). Serotonergic modulation enables pathwayspecific plasticity in a developing sensory circuit in Drosophila. Neuron, 95(3), 623-638.e4. https://doi.org/10.1016/j.neuron.2017.06.034

Kaun, K. R., Azanchi, R., Maung, Z., Hirsh, J., \& Heberlein, U. (2011). A Drosophila model for alcohol reward. Nature Neuroscience, 14(5), 612-619. https://doi.org/10.1038/nn.2805

Khuong, T. M., Wang, Q.-P., Manion, J., Oyston, L. J., Lau, M.-T., Towler, H., Lin, Y. Q., \& Neely, G. G. (2019). Nerve injury drives a heightened state of vigilance and neuropathic sensitization in Drosophila. Science Advances, 5(7), eaaw4099. https://doi.org/10.1126/sciadv.aaw4099

Kreienkamp, H.-J., Larusson, H. J., Witte, I., Roeder, T., Birgul, N., Honck, H.-H., Harder, S., Ellinghausen, G., Buck, F., \& Richter, D. (2002). Functional annotation of two orphan G-proteincoupled receptors, Drostar1 and -2, from Drosophila melanogaster and their ligands by reverse pharmacology. The Journal of Biological Chemistry, 277(42), 39937-39943. https://doi.org/10.1074/jbc.M206931200

Kvello, P., Almaas, T. J., \& Mustaparta, H. (2006). A confined taste area in a lepidopteran brain. Arthropod Structure E Development, 35(1), 35-45. https://doi.org/10.1016/j.asd.2005.10.003

Lopez-Bellido, R., Himmel, N. J., Gutstein, H. B., Cox, D. N., \& Galko, M. J. (2019). An assay for chemical nociception in Drosophila larvae. Philosophical Transactions of the Royal Society B: Biological Sciences, 374(1785), 20190282. https://doi.org/10.1098/rstb.2019.0282

Marella, S., Fischler, W., Kong, P., Asgarian, S., Rueckert, E., \& Scott, K. (2006). Imaging taste responses in the fly brain reveals a functional map of taste category and behavior. Neuron, 49(2), $285-295$. https://doi.org/10.1016/j.neuron.2005.11.037

Mikhalevich, I., \& Powell, R. (2020). Minds without spines: Evolutionarily inclusive animal ethics. https://doi.org/10.51291/2377-7478.1527

Milinkeviciute, G., Gentile, C., \& Neely, G. G. (2012). Drosophila as a tool for studying the conserved genetics of pain. Clinical Genetics, 82(4), 359-366. https://doi.org/10.1111/j.1399-0004.2012.01941.x

Millan, M. J. (2002). Descending control of pain. Progress in Neurobiology, 66(6), 355-474. https://doi.org/10.1016/S0301-0082(02)00009-6

Mirabeau, O., \& Joly, J.-S. (2013). Molecular evolution of peptidergic signaling systems in bilaterians. Proceedings of the National Academy of Sciences, 110(22), E2028-E2037. https://doi.org/10.1073/pnas.1219956110

Morélot-Panzini, C., Mayaux, J., Hug, F., Willer, J.-C., \& Similowski, T. (2014). Analgesic effects of dyspnoea: "Air hunger" does not inhibit the spinal nociception reflex in humans. Respiratory Physiology \& Neurobiology, 190, 81-85. https://doi.org/10.1016/j.resp.2013.09.012

Nässel, D. R. (2021). Leucokinin and associated neuropeptides regulate multiple aspects of physiology and behavior in Drosophila. International Journal of Molecular Sciences, 22(4), 1940. https://doi.org/10.3390/ijms22041940

Neely, G. G., Hess, A., Costigan, M., Keene, A. C., Goulas, S., Langeslag, M., Griffin, R. S., Belfer, I., Dai, F., Smith, S. B., Diatchenko, L., Gupta, V., Xia, C., Amann, S., Kreitz, S., Heindl-Erdmann, C., Wolz, S., Ly, C. V., Arora, S., ... Penninger, J. M. (2010). A Genome-wide Drosophila screen for heat nociception identifies $\alpha 2 \delta 3$ as an evolutionarily conserved pain gene. Cell, 143(4), 628-638. https://doi.org/10.1016/j.cell.2010.09.047

Ohashi, H., \& Sakai, T. (2018). Leucokinin signaling regulates hunger-driven reduction of behavioral responses to noxious heat in Drosophila. Biochemical and Biophysical Research Communications, 499(2), 221-226. https://doi.org/10.1016/j.bbrc.2018.03.132 
Ohyama, T., Schneider-Mizell, C. M., Fetter, R. D., Aleman, J. V., Franconville, R., Rivera-Alba, M., Mensh, B. D., Branson, K. M., Simpson, J. H., Truman, J. W., Cardona, A., \& Zlatic, M. (2015). A multilevel multimodal circuit enhances action selection in Drosophila. Nature, 520(7549), 633-639. https://doi.org/10.1038/nature14297

Okusawa, S., Kohsaka, H., \& Nose, A. (2014). Serotonin and downstream leucokinin neurons modulate larval turning behavior in Drosophila. Journal of Neuroscience, 34(7), 2544-2558. https://doi.org/10.1523/JNEUROSCI.3500-13.2014

Ossipov, M. H., Dussor, G. O., \& Porreca, F. (2010). Central modulation of pain. The Journal of Clinical Investigation, 120(11), 3779-3787. https://doi.org/10.1172/JCI43766

Ossipov, M. H., Morimura, K., \& Porreca, F. (2014). Descending pain modulation and chronification of pain. Current Opinion in Supportive and Palliative Care, 8(2), 143-151. https://doi.org/10.1097/SPC.0000000000000055

Rhudy, J. L., Güereca, Y. M., Kuhn, B. L., Palit, S., \& Flaten, M. A. (2018). The influence of placebo analgesia manipulations on pain report, the nociceptive flexion reflex, and autonomic responses to pain. The Journal of Pain, 19(11), 1257-1274. https://doi.org/10.1016/j.jpain.2018.04.012

Rhudy, J. L., Williams, A. E., McCabe, K. M., Rambo, P. L., \& Russell, J. L. (2006). Emotional modulation of spinal nociception and pain: The impact of predictable noxious stimulation. Pain, 126(1), 221233. https://doi.org/10.1016/j.pain.2006.06.027

Schwartz, S. K., Wagner, W. E., \& Hebets, E. A. (2016). Males Can Benefit from Sexual Cannibalism facilitated by self-sacrifice. Current Biology, 26(20), 2794-2799. https://doi.org/10.1016/j.cub.2016.08.010

Smith, J. A. (1991). A question of pain in invertebrates. ILAR Journal, 33(1-2), $25-31$. https://doi.org/10.1093/ilar.33.1-2.25

Solvi, C., Al-Khudhairy, S. G., \& Chittka, L. (2020). Bumblebees display cross-modal object recognition between visual and tactile senses. Science, 367(6480), 910-912. https://doi.org/10.1126/science.aay8064

Solvi, C., Baciadonna, L., \& Chittka, L. (2016). Unexpected rewards induce dopamine-dependent positive emotion-like state changes in bumblebees. Science, 353(6307), 1529-1531. https://doi.org/10.1126/science.aaf4454

Tabuena, D. R., Solis, A., Geraldi, K., Moffatt, C. A., \& Fuse, M. (2017). Central neural alterations predominate in an insect model of nociceptive sensitization. Journal of Comparative Neurology, 525(5), 1176-1191. https://doi.org/10.1002/cne.24124

Tillu, D. V., Gebhart, G. F., \& Sluka, K. A. (2008). Descending facilitatory pathways from the RVM initiate and maintain bilateral hyperalgesia after muscle insult. PAIN, 136(3), 331-339. https://doi.org/10.1016/j.pain.2007.07.011

Tracey, W. D. (2017). Nociception. Current Biology, 27(4), R129-R133. https://doi.org/10.1016/j.cub.2017.01.037

Tracey, W. D., Wilson, R. I., Laurent, G., \& Benzer, S. (2003). Painless, a Drosophila gene essential for nociception. Cell, 113(2), 261-273. https://doi.org/10.1016/S0092-8674(03)00272-1

Walters, E., Illich, P., Weeks, J., \& Lewin, M. (2001). Defensive responses of larval Manduca sexta and their sensitization by noxious stimuli in the laboratory and field. Journal of Experimental Biology, 204(3), 457-469. https://doi.org/10.1242/jeb.204.3.457

Wang, Z., Singhvi, A., Kong, P., \& Scott, K. (2004). Taste representations in the Drosophila brain. Cell, 117(7), 981-991. https://doi.org/10.1016/j.cell.2004.06.011

Yarali, A., Niewalda, T., Chen, Y., Tanimoto, H., Duerrnagel, S., \& Gerber, B. (2008). 'Pain relief' learning in fruit flies. Animal Behaviour, 76(4), 1173-1185. https://doi.org/10.1016/j.anbehav.2008.05.025

Yashiro, E., Nozaki-Taguchi, N., Isono, S., \& Nishino, T. (2011). Effects of different forms of dyspnoea on pain perception induced by cold-pressor test. Respiratory Physiology \& Neurobiology, 177(3), 320326. https://doi.org/10.1016/j.resp.2011.05.013 